\title{
Paradoxos De Uma Performance: The Great Learning (Paragraph 6) de Cornelius Cardew
}

\section{Paradoxes of a Performance: A Grande Aprendizagem (Parágrafo 6) de Cornelius}

DOI: $10.46814 /$ lajdv3n2-028

Recebimento dos originais: 23/12/2020

Aceitação para publicação: 26/02/2021

\author{
Carlos Arthur Avezum Pereira \\ Doutor em Música (USP) \\ E-mail: cavezum@gmail.com
}

\section{RESUMO}

The Great Learning é uma composição musical experimental que foi afetada pelas contradições estético-políticas vivenciadas pelo seu compositor, Cornelius Cardew, durante o período em que foi composta (1968-1971). Nesse período Cardew questionou uma "estética" vanguardista na música, além das suas próprias obras que tiveram a influência de tal estética. O presente artigo contextualiza esse período vivido pelo compositor para, em seguida, discutir algumas reflexões sobre uma performance dessa obra, a qual foi realizada pelo NuSom. Tais reflexões concentram-se no mote 'música para músicos-não treinados realizada por músicos-treinados', sugerindo assim uma relação indireta com essas contradições estético-políticas.

Palavras-chave: The Great Learning, Música Experimental, Notação Verbal, Performance, Cornelius Cardew.

\begin{abstract}
The Great Learning is an experimental musical composition that was affected by the aesthetic-political contradictions experienced by its composer, Cornelius Cardew, during the period in which it was composed (1968-1971). In this period Cardew questioned an avant-garde "aesthetic" in music, in addition to his own works that were influenced by such an aesthetic. The present article contextualizes this period lived by the composer to then discuss some reflections about a performance of this work, which was performed by NuSom. These reflections focus on the motto 'music for untrained musicians performed by trained musicians', thus suggesting an indirect relationship with these aesthetic-political contradictions.
\end{abstract}

Keywords: The Great Learning, Experimental Music, Verbal Notation, Performance, Cornelius Cardew.

\section{INTRODUÇÃO}

O presente texto trata de algumas reflexões pessoais do autor obtidas a partir da experiência nos ensaios e na apresentação da performance do "Parágrafo 6" da peça The Great Learning do compositor Cornelius Cardew no evento “¿Música? 9 - Partituras Verbais”. O evento foi organizado pelo NuSom (Núcleo de Pesquisa em Sonologia da Universidade de São Paulo) - do qual o autor faz 
parte - e realizado em 29/05/2014 no Ibrasotope - núcleo de música experimental - com sede na cidade de São Paulo. As reflexões propostas neste artigo buscam demonstrar como certas inovações do fazer musical contemporâneo são articuladas em um grupo de pesquisa acadêmico, levantando questões que contribuem para a produção do conhecimento na área da música. Tais questões concentram-se no mote 'música para músicos-não treinados realizada por músicos-treinados', e tecem uma relação indireta com as contradições estético-políticas vivenciadas pelo compositor de The Great Learning no período em que foi composta. Este cenário é melhor compreendido a partir de uma visão do contexto histórico do compositor na época da criação de The Great Learning.

O compositor de The Great Learning, Cornelius Cardew (1936-1981), foi um compositor inglês vanguardista que também esteve inserido no ambiente acadêmico, pois estudou durante a década de 1950 na Royal Academy of Music, conservatório que pertence à Universidade de Londres, frequentada por grandes músicos do Reino Unido. Nas décadas seguintes, participou dos grupos de improvisação e música experimental, AMM e Scratch Orchestra. A improvisação musical - assim como no free jazz - era tida por alguns compositores da vanguarda, tais como Cornelius Cardew e Vinko Globokar, como um "símbolo de liberdade” político-musical contra instituições repressoras (LEWIS, 1996).

Assim como a escola estadunidense da música experimental das primeiras décadas da segunda metade do século XX liderada por John Cage, Cardew também buscava uma igualdade de equilíbrio nas responsabilidades musicais atribuídas ao compositor e ao performer. Segundo Virginia Anderson (2011), havia nas primeiras obras experimentais e nos textos sobre notação musical do compositor uma notável clareza na compreensão do equilíbrio desses papeis.

Nos anos 1970, entusiasmado com os ideais do comunismo, Cardew fez parte de um pequeno grupo de caráter maoísta, filiado a um grupo maior denominado Partido Comunista da Inglaterra, mais fundamentado na linha marxista-leninista. Esta relação demonstrou como os ideais políticos do compositor se refletiram em sua produção composicional no que se refere aos últimos dez anos de sua vida - momento em que se filia ao partido comunista inglês. Nesse momento, o compositor foi gradativamente renunciando à música experimental.

The Great Learning - composta entre os anos de 1968 e 1971 para a Scratch Orchestra - pode ser considerada como uma de suas últimas composições experimentais, mas uma de suas primeiras obras que, possivelmente, absorvem os primórdios de seus ideais comunistas da década de 1970, principalmente no que diz respeito às suas 'reformas' posteriores na composição, as quais foram abandonadas mais tarde. No presente texto, são expostas questões - surgidas a partir de reflexões sobre uma performance da obra e seus respectivos ensaios - as quais se relacionam com dois fatores contrastantes: 1) a performance do Parágrafo 6 deve ser realizada por 'músicos não-treinados', conforme as indicações de Cardew (1968-1971) na partitura e; 2) a performance em questão foi 
realizada por músicos com experiências musicais já consolidadas - os músicos do NuSom.

The Great Learning é uma composição inspirada nos primeiros sete parágrafos da obra literáriafilosófica homônima de Confúcio (552 a.C. - 489 a.C.), filósofo chinês, e de seus discípulos. Essa obra de Cardew pode ser considerada como uma síntese das técnicas da música experimental, visto que, utilizou-se desde a notação musical com o uso de palavras até a notação gráfica ou tradicional (ANDERSON, 2004). Contudo, Cardew repudiou-a poucos anos após ela ser composta (momento em que se filia ao partido comunista britânico), alegando o caráter contrarrevolucionário dessa composição. Conforme atesta Tilbury (2004, tradução nossa), "No início dos anos setenta, Cardew gastou tempo e energia consideráveis em criticar e repudiar suas obras anteriores, incluindo The Great Learning".

Cardew, foi assistente de Stockhausen entre os anos de 1958 e 1960, no entanto, posteriormente, o compositor se revolta contra seu mestre, chegando a publicar um livro com o título de Stockhausen Serves Imperialism, lançado em 1974. Ao final desse livro, Cardew faz uma revisão crítica de sua composição The Great Learning, apontando como os confucionistas foram reacionários durante toda a história de lutas de classes na China que foi iniciada antes mesmo do surgimento de Confúcio e perdura até a atualidade. Segundo Cardew (1974, p. 95, tradução nossa), os confucionistas “Ao defenderem o renascimento da antiga cultura ritual, eles estavam defendendo um retorno ao antigo sistema social de escravidão, todos sob o lema da 'benevolência e justiça'”. No referido livro, também encontram-se relações entre as doutrinas confucionistas, o capitalismo e o fascismo.

Cardew denuncia ainda em Stockhausen Servers Imperialism, Ezra Pound - o tradutor do texto The Great Learning de Confúcio para o inglês - como um ativo apoiador público do regime fascista e de Mussolini, respectivamente, na década de 1930 e durante a Segunda Guerra Mundial. A aproximação com a obra de Ezra Pound é justificada pelo compositor por sua inserção nas abstrações dos movimentos de vanguarda que, posteriormente, os considerou como reflexos de uma 'deseducação burguesa'. Diante de uma mudança de consciência política por parte do compositor, este resolve 'reformar' a composição com o intuito de servi-la à classe trabalhadora e aos ideais comunistas. No entanto, mais tarde, resolve apresentá-la sem reforma, alegando que o “[...] reformismo é uma tendência ideológica que emana da burguesia" que deseja eliminar apenas os sintomas da opressão para esconder os verdadeiros fatos que a causam (CARDEW, 1974, p. 103, tradução nossa). Dessa forma, Cardew declarava que, como compositor burguês, tinha a autonomia revelar os fatos sobre os compositores burgueses da vanguarda e sobre a sua própria composição The Great Learning.

Na primeira metade da década de 1970, a Scratch Orchestra é dissolvida e Cardew abandona a música experimental. O compositor dedica sua música a causas políticas, adotando um estilo populista tonal e neotonal em suas composições até o final de sua vida em 1981. Apesar desse repúdio às suas 
próprias obras vanguardistas, presumindo-se seu caráter antipopular, é interessante notar que Treatise - uma de suas obras mais importantes que insere-se nesse período (década de 1960) - teve uma parte gravada em CD por um grupo de música popular, o grupo de rock experimental Sonic Youth em 1999 em seu álbum SYR4: Goodbye 20th Century (SONIC YOUTH, 1999). Assim, vemos - paradoxalmente à visão populista antivanguarda de Cardew sobre a música - um exemplo de obra com um caráter vanguardista - composta por ele - que foi interpretada por um grupo musical popular.

\section{METODOLOGIA}

A partitura do Parágrafo 6 de The Great Learning, consiste de instruções verbais antecedidas pela tradução em inglês de cada caractere do texto original em chinês no qual a obra foi inspirada. A cada tradução em letras maiúsculas de cada caractere seguem-se as instruções verbais de execução musical que, de uma forma ou de outra, resultam em um modelo instrumental, visto que, são instruções claras para o performer executar (ou ouvir) categorias de sons, tais como: isolados, sincronizados, opcionais, par de sons, acidentais, incidentais, etc.

Na partitura, as instruções que seguem a tradução em inglês do caractere são baseadas nas interpretações das formas gráficas obtidas pelos movimentos das pinceladas registradas no texto original. Por exemplo, em “'tian’, que significa 'a extensão acima dos seres humanos', ou o céu. Esse caractere é feito, fazendo duas linhas horizontais, seguidas por duas pinceladas curvadas para baixo, o que corresponde ao par de sons, e ao par de sons opcionais" (ANDERSON, 2004, tradução nossa).

O tipo de procedimento composicional de interpretação gráfica dos caracteres chineses que, transformados em notação verbal para estruturar e organizar o material adotado por Cardew na composição do Parágrafo 6 - e em outros Parágrafos de The Great Learning -, refletem muito mais uma aproximação com a escola estadunidense da música experimental do que os métodos da escola europeia da vanguarda pós-serialista. Segundo Anderson (2004), os sons deveriam ser executados em respostas às ações dos outros performers, criando uma espécie de 'rede' inspirada na obra de Christian Wolff, compositor da Escola de Nova Iorque a quem foi dedicada a composição do Parágrafo 6. Por exemplo, na performance de Duo II for pianists (1958) de Wolff, os pianistas respondem prontamente a ações musicais um do outro sem deixar silêncios entre uma resposta e outra, embora ocorram pausas em meio as suas próprias respostas que variam dentro de uma gama de possibilidades que dependem das respostas um do outro.

A mente do performer está bastante ocupada para dividir ela mesma em parte consciente e nãoconsciente. Essas partes, contudo, ainda estão presentes. O que tem que acontecer é simplesmente uma completa mudança de direção. Antes que a parte consciente defronte a parte não-consciente da mente, a parte consciente, por urgência e indeterminação da situação, voltase para a parte não-consciente (CAGE, 1961, p. 39, tradução nossa). 
A adoção da notação verbal na composição possibilita uma sorte de resultados indeterminados em sua atualização na performance. Essa atitude de caráter experimentalista, assume a real função da notação musical de qualquer tipo, que é a de descrever as ações que devem ser executadas pelo músico para a produção do som. Embora mesmo que uma nota escrita seja uma representação bastante limitada para o som (dessa nota) que se modifica a cada nova situação da sua execução (ambiente, intérprete, instrumento, ou mesmo um novo momento, dentre outras situações), ainda nos dias de hoje, a partitura tradicional presta-se como ferramenta de análise musical no âmbito da musicologia tradicional. O que, dessa forma, não custa lembrar da importância da música experimental no que diz respeito aos avanços que ela pode trazer para a musicologia.

Dentre os músicos do NuSom que realizaram a performance do Páragrafo 6, alguns deles elaboraram suas próprias notações gráficas com fins de facilitar a leitura da obra (escrita originalmente com notação verbal) durante a performance. Abaixo, nas Figuras 1 e 2 são reproduzidas as imagens da partitura e da sua bula de execução, respectivamente, preparada pelo autor do presente texto, quem participou da performance apresentada em público. Antes da performance realizada pelo NuSom, o performer- quem produziu a partitura gráfica (Figura 1) e a sua bula de execução (Figura 2) - não tinha, naquele momento, o conhecimento do processo que o compositor utilizou na elaboração da notação verbal do Parágrafo 6, o qual consistia na interpretação das pinceladas dos caracteres chineses no texto original confucionista comentado anteriormente.

Figura 1: notação gráfica do Parágrafo 6 de The Great Learning (Cornelius Cardew) elaborada pelo autor a partir da notação verbal da versão original

THE GREAT LEARNING - PARAGRAPH 6 - (CORNELIUS CARDEW)

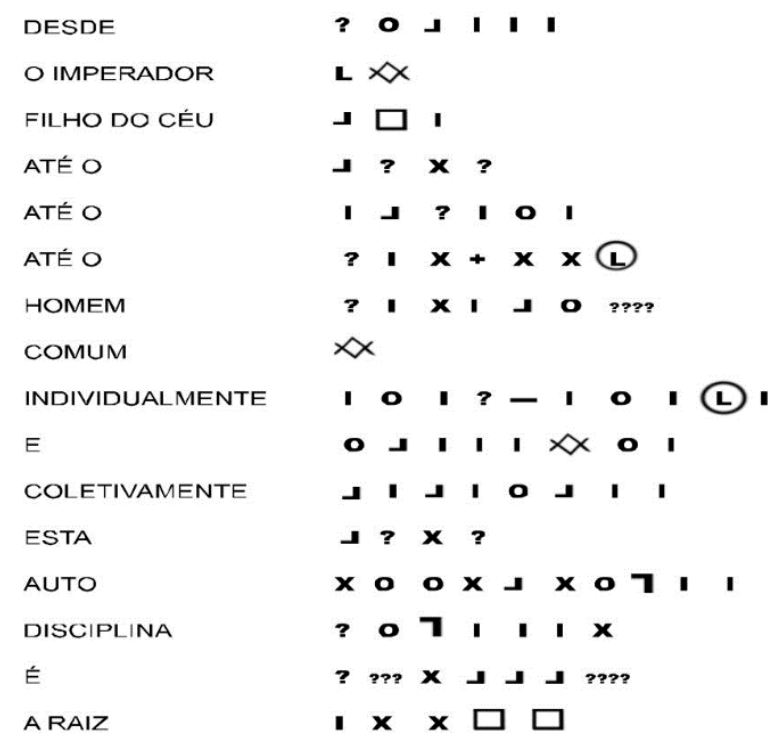


Figura 2: bula da notação gráfica do Parágrafo 6 de The Great Learning (Cornelius Cardew) elaborada pelo autor

THE GREAT LEARNING - PARAGRAPH 6
(CORNELIUS CARDEW)

É interessante notar como o processo feito por Cardew de interpretar as imagens das pinceladas dos caracteres chineses e, segundo sua própria lógica, mapeá-las a categorias de sons - descritas verbalmente na partitura original -, se assemelha ao processo inverso feito pelo performer que produziu a notação gráfica (Figura 1), ou seja, produziu-se uma partitura gráfica a partir da interpretação de uma escrita textual.

\section{DISCUSSÃO DOS RESULTADOS}

Conforme dito anteriormente, The Great Learning, foi composta para ser executada pela Scratch Orchestra, que era constituída por diversos artistas como "estudantes de música, artistas visuais, atores, dançarinos, e pessoas sem experiência anterior em artes” (ANDERSON, 2004, tradução nossa). No Parágrafo 6 da partitura, é observado que sua execução é destinada a 'músicos nãotreinados', o que supostamente gera a hipótese de que este Parágrafo devia ser tocado pelos artistas da Scratch Orchestra, os quais não eram estudantes de música, tais como aqueles citados acima.

Essa relação da música experimental com 'músicos não-treinados' pode ainda ser vista na relação desse tipo de prática musical com iniciativas na educação básica nesta direção, evidenciando assim os anseios democráticos de alguns compositores. Ao desenvolver um projeto de educação musical com alunos de escolas públicas através da Universidade Estadual de Londrina, Ieger e outros (2021, p. 788), comentam que "sempre esteve claro a musicalidade imbuída a cada indivíduo independentemente de seu contexto social". É bem provável que essa era a visão de Cardew a respeito da experiência musical a partir da época em que realizou a composição de The Great Learning. Convém 
ressaltar, no entanto, que tal concepção democrática da experiência musical não significa, necessariamente, a limitação estética dessa experiência quando comparada ao virtuosismo de 'músicos treinados'. Ieger e outros (2021, p. 789), comentam que o virtuosismo em música pode não ser apenas aquele

[...] técnico-performático, mas sim o virtuosismo que buscamos quando evocamos e incitamos indivíduos a se expressarem de forma livre, 'o virtuosismo da expressão em música'.

O processo de criação parte de pressupostos subjetivos de cada indivíduo, que necessitam da oportunidade e espaço para se expressarem livremente.

Por outro lado, a performance realizada em 29/05/2014, comentada no início do texto, foi realizada por doze músicos-pesquisadores do NuSom que possuem uma experiência musical já consolidada, ou seja, são 'músicos treinados'. Dessa forma, que tipos de problema foram encontrados na performance de uma partitura destinada a 'músicos não-treinados' mas que foi realizada por 'músicos treinados'?

Uma questão que surgiu na execução da obra referente à dicotomia 'músicos não-treinados' (da partitura) e 'músicos treinados' (da performance do NuSom) foi com relação ao seu material sonoro. Cardew (1968-1971, tradução nossa), define nas notas de performance da partitura do Parágrafo 6: "cada som de uma fonte diferente ou todos os sons de uma mesma fonte, ou qualquer gradação entre estas duas situações". No entanto, nenhum dos doze músicos do NuSom tocou todos os sons vindos de uma mesma e única fonte sonora. Os músicos, em comum acordo, decidiram que cada um deles deveria tocar sons de cinco diferentes fontes acústicas (tais como aquelas que o compositor sugere: pedras, apitos, assobios, cantos, falas, reco-recos, etc.). Isso se deu devido à possibilidade de uma monotonia provocada pela homogeneidade tímbrica de uma ou poucas fontes sonoras como sugerido na partitura de Cardew. Além desse acordo, outros também foram negociados durante os ensaios anteriores à apresentação ocorrida em 29/05/2014, e são descritos a seguir.

Em termos de duração dos sons, também havia uma certa homogeneidade na performance, pois, Cardew define a palavra 'som' nas notas de performance da seguinte forma: 'Um 'som', sem adjetivo qualificador, significa um tipo mais definido de som com uma certa presença. Sons são geralmente curtos e suaves" (CARDEW, 1968-1971). Assim, a grande maioria dos sons que ocorriam na performance tinham uma duração curta, excetuando os momentos em que o performer deveria tocar a rara indicação de 'um som alto ou longo', que também poderia aparecer em sua forma 'sincronizada' ou 'opcional'.

Outra questão discutida no grupo se referia a busca de contrastes sonoros, pois, mesmo com variadas fontes, a indeterminação dos resultados sonoros que a composição ocasiona, causa uma certa homogeneidade em termos de forma musical devido à miscelânea de ataques não-sincronizados com 
variados timbres. De acordo com Nyman (1999, p. 125, tradução nossa),

[...] as singulares partituras dos Parágrafos 6 e 7 proporcionam um ritual pessoal que adentra uma rede comunitária semelhante a um clima suave ou fortemente colorido de silêncio. No Parágrafo 6, a responsabilidade pessoal para realizar os sons é sutil, uma vez que, na maior parte do tempo o performer deve esperar para analisar o contexto correto em que se colocam pequenos sons, cujo lugar não é detalhado pelo compositor. Por exemplo, alguém deve tocar sons isolados ou sincronizados, que acontecem em diferentes pontos para diferentes performers que tocam a partitura em suas próprias velocidades. O contexto é, portanto, diferente para cada performer: o seu contexto (um silêncio em que se coloca um som isolado) depende dos outros contextos, e é ao mesmo tempo parte desses outros contextos.

Dessa forma, é notável, o quanto a partitura do Parágrafo 6 pode provocar tal homogeneidade formal, inclusive pelo fato de que essas sutilezas de sua performance também incorporam o 'erro'. Na partitura de Cardew (1968-1971), solicita-se ao(s) performer(s) a realização de sons sincronizados com outro(s) performer(s), no entanto, a indicação nas notas de execução de que "No caso de falha na produção de um som devidamente 'isolado' ou 'sincronizado', não há limite para o número de tentativas que podem ser feitas, mas não há a obrigatoriedade de se tentar mais de uma vez", abria-se a possibilidade de tais sons não ocorrerem. Essa possibilidade se torna mais forte pela primeira nota que diz: "Qualquer número de músicos se movem independentemente pelo material na ordem escrita. Não há obrigação de se atingir o fim" (CARDEW, 1968-1971).

Diante da possibilidade de uma homogeneidade formal da composição, o grupo decidiu aproveitar os momentos de 'pausas' indicados na partitura, de forma a estender suas durações. Apesar de haver a indicação de dois tipos de pausas - 'pausa longa' e 'pausa geral' - não houve discussão no grupo sobre uma possível diferença entre elas, apenas optou-se - em um acordo coletivo -, pelas suas durações estendidas com o intuito de gerar um contraste formal por meio da relação entre 'som' e 'silêncio'. A 'pausa geral' é definida pelo compositor como ‘quando todos estão em silêncio e imóveis', possibilitando, assim, variadas interpretações dessa definição por cada músico, cujas execuções influenciavam na execução de todos os outros músicos.

$\mathrm{Na}$ busca destes contraste sonoros entre som e silêncio, muitas vezes, o imediatismo sequencial dos sons indicados na partitura e seguidos de forma individual por cada performer foi sacrificado. Isso ocorria ao se estender a duração das 'pausas gerais' escritas, devido ao acordo que foi realizado entre os músicos nos ensaios. A extensão temporal dessas pausas foi considerada em relação às suas durações nos primeiros ensaios nos quais, muitas vezes, alguns dos performers interpretavam tais pausas de maneira mais rápida, ou seja, logo que ouviam um silêncio coletivo entre todos, imediatamente tocavam o próximo som do ponto em que estavam na sequência da partitura, interrompendo a percepção de uma longa pausa coletiva como possível elemento de estruturação formal da performance idealizada pelo NuSom. 
Apesar da individualidade de execução da sequência na partitura ter sido sacrificada algumas vezes pelos acordos do grupo, o que poderia resultar em uma perda de acessibilidade da notação verbal para o povo (público) - que era um mote para o compositor -, a extensão duracional das pausas, por outro lado, aguçava ainda mais a escuta. Dessa forma, os sons definidos por Cardew - na notação do Parágrafo 6 - como 'curtos' e 'sutis' assemelhavam-se aos sons do ambiente que, a princípio, estavam fora da performance, causando uma maior apreensão nos músicos e maior imersão no público que, ao tentar diferenciar os 'sons da performance musical' dos 'sons do silêncio do ambiente', terminavam por sentir que também participavam da performance.

\section{CONSIDERAÇÕES FINAIS}

As escolhas e negociações, tais como, por exemplo, a utilização de várias fontes sonoras e a extensão da duração das pausas para gerar contraste formal, realizadas pelos 'músicos treinados' do NuSom ou de qualquer outro grupo de músicos treinados - principalmente no contexto da música experimental -, provavelmente não seriam as mesmas escolhas feitas por 'músicos não-treinados', que, segundo as indicações da partitura, são aqueles quem deveriam executar o Parágrafo 6 de The Great Learning. Isso pode ser observado nas mudanças de estratégias musicais que - mesmo com poucos ensaios -, ocorreram desde o primeiro ensaio da peça realizado pelo NuSom até a sua apresentação em público. Embora o objetivo do presente trabalho não fosse o de comparar performances do Parágrafo 6 realizadas por 'músicos treinados' com outras realizadas por 'músicos não-treinados', é notável que as estratégias de performance empregadas pelos músicos do NuSom demonstram conhecimento, ou ainda, 'treinamento' musical - situação oposta ao indicado pela partitura. Embora alguns aspectos de uma concepção mais democrática da performance musical feita por Cardew na partitura do Parágrafo 6 de The Great Learning fossem sacrificados pelo NuSom em sua performance, mais especificamente aqueles relacionados com a execução, convém observar que tal sacrifício também se deu por uma questão democrática: a questão da escuta. A partitura verbal do Parágrafo 6 - distribuída ao público ouvinte - pôde ser seguida durante a performance, de tal forma que tais sacrifícios em favor dos contrastes formais facilitaram a possibilidade do público compreender a obra. Mesmo que cada músico pudesse estar em um ponto diferente da partitura, alguém do público poderia acompanhar momentaneamente, ou durante toda a performance, a execução individual de algum desses músicos ao perceber pela escuta a sincronia de sua própria leitura com a leitura do músico, o que ampliaria a sua percepção global da obra.

Utilizada pelo movimento da música experimental, a notação verbal é uma tentativa de crítica à tradição musical que separa claramente os papeis dos compositores, dos intérpretes e do público. Essa crítica é tipicamente feita à especialização laboriosa na obtenção de faculdades e habilidades técnico- 
instrumentais destinadas somente aos 'iniciados' de determinada arte. Assim, por mais que a performance do Paragraph 6 seja complexa, conforme discutimos neste trabalho, ela pôde ser entendida e concebida para 'músicos não-treinados' (conforme as indicações do compositor) devido à natureza linguística de sua partitura.

The Great Learning, mais especificamente o Parágrafo 6, pode ser considerada uma obra que levanta discussões no contexto da música experimental, as quais visam propor uma abordagem mais democrática da atividade musical. Apesar dessa abordagem, nos primeiros anos seguidos ao término da obra - no início da década de 1970 -, The Great Learning torna-se alvo de crítica de seu próprio compositor Cornelius Cardew, devido à sua tomada radical de posicionamento político em favor do Comunismo. Contradições e especulações do início da carreira do compositor que influenciaram a poética dessa obra, além de questões musicais relacionadas à dicotomia 'música para músicos-não treinados realizada por músicos-treinados' foram discutidas no presente trabalho. Tais questões revelaram alguns paradoxos levantados pela performance dessa obra realizada pelo $\mathrm{NuSom}$. Paradoxos que, muitas vezes, podem ser característicos da música experimental e que promovem férteis debates para a pesquisa em performance da música contemporânea. 


\section{REFERÊNCIAS BIBLIOGRÁFICAS}

ANDERSON, Virginia. Chinese Characters and Experimental Structure in Cornelius Cardew's The Great Learning. Jems: Journal of Experimental Music Studies, 2004. Disponível em: <http://www.users.waitrose.com/ chobbs/Chinesegl.html>. Acesso em: 9 jun. 2014.

Cornelius Cardew lives. Open Democracy, Reino Unido, 2011. Disponível em: <https://www.opendemocracy.net/arts-Music/cardew_3509.jsp>. Acesso em: 28 jul. 2014.

CAGE, John. Silence. Midletown: Wesleyan University Press, 1961 sicepe.

CARDEW, Cornelius. Stockhausen Serves Imperialism. Originalmente publicado em 1974 por Latimer New Dimensions Limited. London: Ubuclassics, 2004.

The Great Learning. Inglaterra: 1968-1971. 1 Partitura.

IEGER, E.; VENTURA, L.; SUMIGAWA, L.; KLEBER, M. Produção, apropriação e reflexão sobre a difundida música não convencional: uma abordagem objetiva e prática sobre a "Computer Music". Latin American Journal of Development, Curitiba, v. 3, n. 2, p. 784-790, mar./abr. 2021. Disponível em:

<https://latinamericanpublicacoes.com.br/ojs/index.php/jdev/article/view/264>. Acesso em: 12 abr. 2021.

LEWIS, G. E. Improvised music after 1950: afrological and eurological perspectives. Black Music Research Journal, Chicago, v.16, n.1, spring 1996. Disponível em: <http://www.albany.edu/music/451readings/lewis_improv_post1950.pdf>. Acesso em: 30 jul. 2014.

NYMAN, Michael. Experimental Music: Cage and beyond. Second Edition. New York: Cambridge University Press, 1999.

SONIC YOUTH. SYR4: goodbye 20th century. New York City: SYR, 1999. 2 CDs.

TILBURY, John. Cornelius Cardew. Jems: Journal of Experimental Music Studies, 2004. Originalmente publicado em Contact 26, p. 4-11, 1983. Disponível em: <http://www.users.waitrose.com/ chobbs/tilburycardew.html>. Acesso em: 9 jun. 2014. 